\title{
Trop2 is overexpressed in gastric cancer and predicts poor prognosis
}

\author{
Wei Zhao ${ }^{1,2, *}$, Huijun Zhu ${ }^{3, *}$, Shu Zhang ${ }^{3}$, Hongmei Yong ${ }^{4}$, Wei Wang ${ }^{3}$, Yan Zhou ${ }^{5}$, \\ Bing Wang ${ }^{5}$, Jinbo Wen ${ }^{6}$, Zhenning Qiü, Guipeng Ding ${ }^{1}$, Zhenqing Feng ${ }^{1,7,8,9}$, \\ Jin Zhu $\mathbf{u}^{7,10}$ \\ ${ }^{1}$ Department of Pathology, Nanjing Medical University, Nanjing 210029, China \\ ${ }^{2}$ School of Public Health, Nantong University, Nantong 226019, China \\ ${ }^{3}$ Department of Pathology, Affiliated Hospital of Nantong University, Nantong 226019, China \\ ${ }^{4}$ Department of Oncology, Huai'an Hospital Affiliated of Xuzhou Medical College and Huai'an Second People's Hospital, \\ Huai'an 223001, China \\ ${ }^{5}$ Department of Oncology, AoYoung Hospital, Zhangjiagang, Jiangsu 215617, China \\ ${ }^{6}$ Department of Epidemiology, School of Public Health, Nanjing Medical University, Nanjing 210029, China \\ ${ }^{7}$ Key Laboratory of Antibody Technique of Ministry of Health, Nanjing Medical University, Nanjing 210029, China \\ 8 Jiangsu Collaborative Innovation Center for Cancer Personalized Medicine, Nanjing Medical University, Nanjing 210029, \\ China \\ ${ }^{9}$ Key Laboratory of Cancer Biomarkers, Prevent and Treatment, Cancer Center, Nanjing Medical University, Nanjing 210029, China \\ ${ }^{10}$ Huadong Medical Institute of Biotechniques, Nanjing 210029, China \\ *These authors contributed equally to this work
}

Correspondence to: Zhenqing Feng, e-mail: fengzhenqing@njmu.edu.cn

Jin Zhu, e-mail: zhujin1968@njmu.edu.cn

Keywords: Trop2, prognosis, gastric cancer

Received: August 03, $2015 \quad$ Accepted: December 08, 2015

Published: December 22, 2015

\section{ABSTRACT}

The cell surface protein Trop2 is overexpressed in a variety of human cancers. Trop 2 expression increases tumor development and metastasis and reduces patient survival. However, little is known about the role of Trop2 expression and its prognostic value in gastric cancer (GC), particularly in Chinese populations. We analyzed Trop2 expression in GC tissues collected from Chinese GC patients. Quantitative real-time polymerase chain reaction ( $q R T-P C R$ ) and immunohistochemistry on tissue microarrays were performed to assess levels of Trop2 mRNA and protein in GC, and correlations between Trop 2 expression and clinical characteristics and prognosis were analyzed. Trop 2 expression was higher in GC tissues than in neighboring nontumor tissues. Increased Trop2 protein levels in GC were associated with increased differentiation, tumor node metastasis stage, tumor size, lymph node metastasis, distant metastasis, and $\boldsymbol{H}$. pylori infection. GC patients with high Trop 2 expression also had poor overall survival rates. These data suggest Trop2 is a useful prognostic biomarker for GC.

\section{INTRODUCTION}

Gastric cancer (GC) is a leading cause of global cancer-related mortality [1]. GC prevalence is highest in Asia, and the majority of GC patients are diagnosed at an advanced stage [2-3]. Due to the high rates of metastasis and recurrence, the prognosis of GC patients is poor: 5 -year survival rates are less than 20\% [4]. Helicobacter pylori (H. pylori) infection and intestinal metaplasia (IM) are common complications in gastric cancer patients [5-8]. Identifying new genetic markers to help diagnose GC earlier will help to improve cure rates and reduce complications, including $H$. pylori and other chronic gastric infections.

The human trophoblast cell surface (TACSTD2/ Trop2/M1S1/GA733-1) gene is located at chromosome 
1q32 [9]. Trop2 is a 36-kDa single-pass transmembrane protein expressed primarily in epithelial cells [10] and was first identified in human trophoblasts [11]. Trop2 has several binding partners, including Claudin 1, Claudin 7, Cyclin D1, protein kinase C (PKC), PIP2, and insulinlike growth factor 1 (IGF-1) [11, 32-33]. By binding to these targets, Trop 2 affects tight junctions at the epithelial barrier [26]; increases tumor proliferation [34], podosome formation, and Raf and NF-kappa activation [11, 26]; and suppresses IGF-1R signaling [35]. Trop2 is overexpressed in various epithelial tumors [12-15], and its expression correlates with aggressive tumor behavior [16]. In contrast to tumor cells, somatic adult tissues show little or no Trop2 expression $[11,17]$.

Trop2 increases tumor recurrence, progression, and invasiveness [18-21], and has been used as a prognostic marker in several types of cancer [22]. It is overexpressed in oral squamous epithelial cell carcinoma [13], breast cancer [18], colon cancer [23], pancreatic cancer [24], and cervical cancer [25]. It is also upregulated in certain malignant hematological diseases, including Non-Hodgkin's lymphoma (NHL) and leukemia [26]. Antibodies such as human antiTrop2 antibody IgG and fragment Fab, which reduce Trop2 expression, also inhibit cell proliferation, induce apoptosis, and delay migration in some cancer cell types, both in vitro and in vivo [27-31].

The role of Trop2 in GC is less well understood. Muhlmann et al. detected elevated Trop2 expression in a group of 104 Austrian patients with intestinal-type carcinomas [14]. Because the incidence and lethality of GC differs between populations, it would seem useful to explore Trop2 expression levels in both benign and malignant gastric tissues from different patient groups. In this study, we analyzed Trop2 expression in primary GCs from 600 Chinese patients and compared it with expression in matched neighboring non-tumor tissues. We also examined the relationship between Trop2 expression, clinical characteristics, and overall survival in GC.

\section{RESULTS}

\section{Trop2 mRNA was overexpressed in GC tissues}

To investigate the expression of Trop 2 mRNA, we performed qRT-PCR in 41 pairs of GC tissue and matched tumor neighbor tissue. Trop2 mRNA expression was $2.32 \pm 1.44$ fold higher in GC tissues than in matched tumor neighbor tissues ( $p<0.001$, Figure 1).

\section{Trop2 protein was overexpressed in GC tissues}

Trop2 protein, which was localized to the membrane and cytoplasm using immunohistochemistry, was overexpressed in GC tissues (Figure 2). Using the x-tile software program for TMA data analysis (http://www. tissuearray.org/rimmlab), we defined high and low Trop2 expression levels based on overall survival in GC patients. A cutoff value of 130 cells was selected: counts between 0 and 130 were considered low expression, while counts of 131 to 300 were considered high expression. All Trop2 protein levels were classified as "Low" or "High" using these cutoff values prior to analysis.

High Trop2 expression was detected more often in gastric cancer tissues $(66.30 \%, 398 / 600)$ than in matched tumor neighbor tissues $(43.8 \%, 39 / 89)$ (Table 1). However, in Signet ring cell carcinoma, high Trop2 expression was only present in $43.5 \%$ of tissues (10/23). Interestingly, high Trop2 expression was most prevalent in intestinal metaplasia (IM) tissues $(80.00 \%, 24 / 30)$. Low Trop2 expression levels were found less frequently in other gastric tissue types, including chronic gastritis $(12.5 \%$, 4/32), low-grade intraepithelial neoplasia $(29.0 \%, 9 / 31)$, and high-grade intraepithelial neoplasia (37.5\%, 18/48).

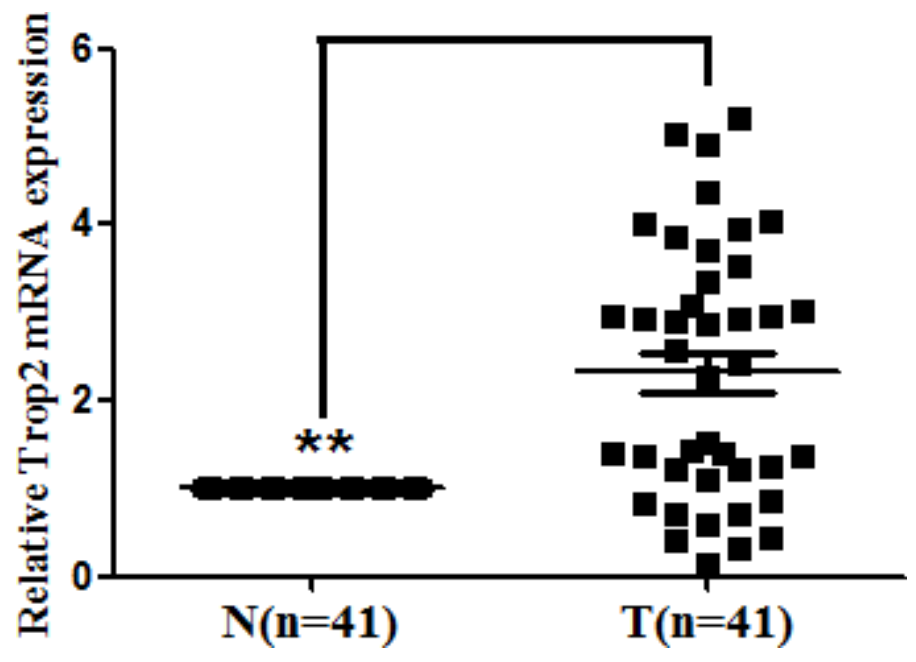

Figure 1: Trop2 mRNA expression in 41 GC tissue pairs. Trop2 mRNA expression was examined by qRT-PCR and normalized to $\beta$-actin. Trop2 mRNA levels were higher in the $41 \mathrm{GC}$ tissues (T) than in matched tumor neighbor tissues $(\mathrm{N})(* * p<0.001)$. 


\section{Trop2 overexpression was associated with more advanced clinical characteristics in GC patients}

We next investigated the relationship between Trop2 protein levels and patient clinical parameters (Table 2). High expression of Trop2 in GC was associated with increased differentiation $\left(\chi^{2}=9.192, p=0.027\right)$, Tumor Node Metastasis (TNM) stage $\left(\chi^{2}=38.939\right.$, $p<0.001)$, tumor size $\left(\chi^{2}=35.576, p<0.001\right)$, lymph node metastases $\left(\chi^{2}=17.638, p<0.001\right)$, distant metastases $\left(\chi^{2}=9.728, p=0.001\right)$, and H. pylori infection $\left(\chi^{2}=7.549, p=0.005\right)$. However, there were no significant associations between Trop2 levels and gender, age, or histology type. (Table 2).

\section{Trop2 protein overexpression was associated with poor prognosis in GC}

We also investigated the relationship between Trop 2 expression and prognostic factors in GC using both univariate and multivariate analyses. High Trop2 expression (HR, 2.474, 95\% CI, 1.765-3.468; $p<0.001$ ) was associated with poor overall survival in the univariate analysis, and with increases in other prognostic markers, including TNM stage (HR, 2.245, 95\% CI, 1.870-2.696; $p<0.001)$ and $H$. pylori infection (HR, 2.696, 95\% CI,
1.795-4.008; $p<0.001$ ) (Table 3). In the multivariate analysis, high Trop2 expression was associated with poor overall survival (HR, 1.819, 95\% CI, 1.213-2.728; $p=0.004)$ and increases in TNM stage (HR, 2.265, 95\% CI, 1.512-3.393; $p<0.001)$ and H. pylori infection (HR, 2.512, 95\% CI, 1.575-4.006; $p<0.001$ ) (Table 3). Kaplan-Meier survival curves showed that Trop2 overexpression was significantly associated with poor overall survival, as well as with TNM stage and $H$. pylori infection. Additionally, high Trop2 expression was associated with lower disease-free survival rates in GC patients (Figure 3). These results suggest that Trop2 expression, TNM stage, and $H$. pylori infection are prognostic markers in GC.

\section{DISCUSSION}

In this study, we used qRT-PCR and immunohistochemistry to examine Trop2 mRNA and protein levels in GC tissues from Chinese patients. Trop2 mRNA levels were much higher in GC tissues than in matched neighboring non-tumor tissues, as is the case in other tumors [34]. However, the relationship between mRNA and protein levels is not strictly linear and involves spatialtemporal disparities. To confirm that protein levels were also elevated in GC, we examined a microarray that

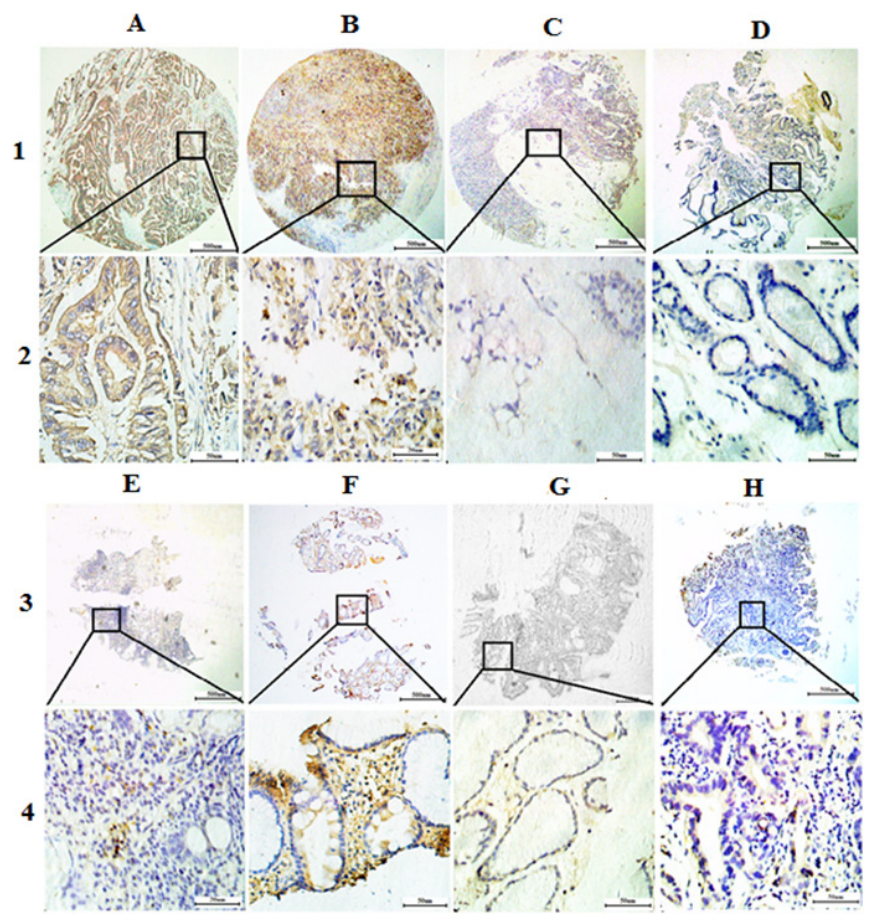

Figure 2: Representative images of Trop2 protein expression in gastric tissue TMA sections. (A) Middle differentiated gastric cancer with high Trop2 expression (IHC score, 300); (B) Poor differentiated gastric cancer with high Trop2 expression (IHC score, 270); (C) Signet ring cell gastric cancer with low Trop2 expression (IHC score, 60); (D) Matched tumor neighbor tissues with low Trop2 expression (IHC score, 30); (E) Chronic gastritis with low Trop2 expression (IHC score, 30); (F) Intestinal metaplasia with high Trop2 expression (IHC score, 260); (G) Low-grade intraepithelial neoplasia with low Trop2 expression (IHC score, 30); (H) High-grade intraepithelial neoplasia with low Trop2 expression (IHC score, 60); Row 1 and 3 are Trop2 staining with $\times 4$ (bar $=500 \mu \mathrm{m}$ ), Row 2 and 4 are Trop2 staining with $\times 40($ bar $=50 \mu \mathrm{m})$. 
Table 1: Trop2 expression in gastric tissues

\begin{tabular}{l} 
Characteristic \\
\cline { 4 - 6 }
\end{tabular}

$\chi^{2}$ and $p$ values for stomach overall includes all types gastric tissues. The $\chi^{2}$ and $p$ values for matched tumor neighbor, chronic gastritis, intestinal metaplasia, low-grade intraepithelial neoplasia, and high-grade intraepithelial neoplasia are in comparison to the cancer group.

Table 2: Associations between high Trop2 expression and clinicopathologic characteristics in GC patients

\begin{tabular}{|c|c|c|c|c|c|}
\hline \multirow{2}{*}{ Characteristic } & \multirow{2}{*}{$n$} & \multicolumn{2}{|c|}{ Trop2 expression (\%) } & \multirow{2}{*}{ Pearson $\chi^{2}$} & \multirow{2}{*}{$p$} \\
\hline & & Low or no & High & & \\
\hline Total & 600 & $202(34.70)$ & $398(66.30)$ & & \\
\hline Gender & & & & 0.557 & 0.504 \\
\hline Male & 428 & $148(34.60)$ & $280(65.40)$ & & \\
\hline Female & 172 & $54(31.40)$ & $118(68.60)$ & & \\
\hline Age & & & & 2.158 & 0.084 \\
\hline$<60$ & 334 & $104(31.10)$ & $230(68.90)$ & & \\
\hline$\geq 60$ & 226 & $98(36.80)$ & $168(63.20)$ & & \\
\hline Histological type & & & & 9.187 & 0.057 \\
\hline Tubular & 524 & $176(33.60)$ & $348(66.40)$ & & \\
\hline Mixed (tubular and mucinous) & 7 & $2(28.60)$ & $5(71.40)$ & & \\
\hline Mucinous & 34 & $10(29.40)$ & $24(70.60)$ & & \\
\hline Signet ring cell & 23 & $13(56.50)$ & $10(43.50)$ & & \\
\hline Others $^{\mathrm{a}}$ & 12 & $1(8.30)$ & $11(91.70)$ & & \\
\hline Differentiation & & & & 9.192 & $0.027 *$ \\
\hline Well & 57 & $28(49.10)$ & $29(50.90)$ & & \\
\hline Moderate & 145 & $52(35.90)$ & $93(64.10)$ & & \\
\hline Poor & 329 & $97(29.50)$ & $232(70.50)$ & & \\
\hline Others $^{\mathrm{b}}$ & 69 & $25(36.20)$ & $44(63.80)$ & & \\
\hline TNM stage & & & & 38.939 & $<0.001 *$ \\
\hline 0 & 18 & $10(50.60)$ & $8(44.40)$ & & \\
\hline $\mathrm{Ia}+\mathrm{Ib}$ & 111 & $60(54.10)$ & $51(45.90)$ & & \\
\hline
\end{tabular}




\begin{tabular}{|l|r|r|r|r|l|}
\hline Ia + IIb & \multicolumn{1}{|c|}{208} & $72(34.60)$ & $136(65.40)$ & & \\
\hline IIIa+ IIIb & 210 & $50(23.80)$ & $160(76.20)$ & & \\
\hline IIIc + IV & 53 & $10(18.90)$ & $43(81.10)$ & & \\
\hline Tumor size & & & & 35.576 & $<\mathbf{0 . 0 0 1}^{*}$ \\
\hline T0 & 18 & $10(55.60)$ & $8(44.40)$ & & \\
\hline T1a+T1b+T2 & 180 & $89(49.40)$ & $91(50.60)$ & & \\
\hline T3+T4a+T4b & 402 & $103(25.60)$ & $299(74.40)$ & & \\
\hline Lymph node metastases & & & & 17.638 & $<\mathbf{0 . 0 0 1}^{*}$ \\
\hline N0 & 227 & $100(44.10)$ & $127(55.90)$ & & \\
\hline N1 & 373 & $102(27.30)$ & $271(72.70)$ & & \\
\hline Distant metastases & & & & 9.728 & $\mathbf{0 . 0 0 1 *}$ \\
\hline M0 & 562 & $198(35.20)$ & $364(64.80)$ & & \\
\hline M1 & 38 & $4(10.50)$ & $34(89.50)$ & & \\
\hline H. pylori infection & & & & 7.549 & $\mathbf{0 . 0 0 5 *}$ \\
\hline Positive & 475 & $147(30.9 \%)$ & $328(69.1 \%)$ & & \\
\hline Negative & 125 & $55(44.0 \%)$ & $70(56.0 \%)$ & & \\
\hline
\end{tabular}

${ }^{a}$ others include: pallipary adenocarcinoma, 5 cases; adeno-squamous carcinoma, 5 cases; squamous cell carcinoma, 3 cases; undifferentiated carcinoma, 2 cases; and neuroendocrine carcinoma, 1 case.

bothers include everything besides tubular and papillary adenocarcinoma.

$* p<0.05$.

Table 3: Univariate and multivariate analysis of prognostic markers for overall survival in gastric cancer

\begin{tabular}{|c|c|c|c|c|c|c|}
\hline & \multicolumn{3}{|c|}{ Univariate analysis } & \multicolumn{3}{|c|}{ Multivariate analysis } \\
\hline & HR & $p>|\mathbf{z}|$ & $95 \% \mathrm{CI}$ & HR & $p>|\mathbf{z}|$ & $95 \% \mathrm{CI}$ \\
\hline \multicolumn{7}{|l|}{ Trop2 expression } \\
\hline High vs Low or no & 2.474 & $0.000 *$ & $1.765-3.468$ & 1.819 & $0.004 *$ & $1.213-2.728$ \\
\hline \multicolumn{7}{|l|}{ Age } \\
\hline$\leq 60$ vs $\geq 60$ & 0.733 & 0.057 & $0.532-1.009$ & - & - & - \\
\hline \multicolumn{7}{|l|}{ Gender } \\
\hline Male vs Female & 1.083 & 0.658 & $0.761-1.541$ & - & - & - \\
\hline \multicolumn{7}{|l|}{ Histological type } \\
\hline $\begin{array}{l}\text { Tubular vs Mixed (tubular and } \\
\text { mucinous) vs Mucinous vs } \\
\text { signet ring cells vs others }\end{array}$ & 0.924 & 0.388 & $0.773-1.105$ & - & - & - \\
\hline \multicolumn{7}{|l|}{ Differentiation } \\
\hline Well vs Moderate vs Poor & 1.168 & 0.115 & $0.963-1.416$ & - & - & - \\
\hline \multicolumn{7}{|l|}{ TNM stage } \\
\hline $\begin{array}{l}0 \text { vs Ia }+ \text { Ib vs IIa }+ \text { IIb vs IIIa }+ \\
\text { IIIb vs IIIc }+ \text { IV }\end{array}$ & 2.245 & $<0.001 *$ & $1.870-2.696$ & 2.265 & $<0.001 *$ & $1.512-3.393$ \\
\hline \multicolumn{7}{|l|}{ Tumor size } \\
\hline Tis vs $\mathrm{T} 1$ vs $\mathrm{T} 2$ vs $\mathrm{T} 3$ vs $\mathrm{T} 4$ & 2.320 & $<0.001 *$ & $1.758-3.062$ & - & - & - \\
\hline
\end{tabular}




\begin{tabular}{|l|l|l|l|l|l|l|}
\hline Lymph node metastases & & & & & \\
\hline N0 vs N1 vs N2 vs N3 & 3.657 & $<\mathbf{0 . 0 0 1 *}$ & $2.611-5.123$ & - & - & - \\
\hline Distant metastases & & & & & & \\
\hline M0 vs M1 & 6.614 & $<\mathbf{0 . 0 0 1 *}$ & $2.317-18.878$ & - & - & - \\
\hline H. pylori infection & & & & & & \\
\hline Positive vs Negative & 2.696 & $<\mathbf{0 . 0 0 1 *}$ & $1.795-4.008$ & 2.512 & $<\mathbf{0 . 0 0 1 *}$ & $1.575-4.006$ \\
\hline
\end{tabular}

a others include: pallipary adenocarcinoma, 5 cases; adeno-squamous carcinoma, 5 cases; squamous cell carcinoma, 3 cases; undifferentiated carcinoma, 2 cases; and neuroendocrine carcinoma, 1 case.

$* p<0.05$.

included 830 samples of gastric tissue, 600 of which were $\mathrm{GC}$, and the associated clinical and follow-up data. Trop2 protein was localized to the cell membrane and cytoplasm. As was the case with mRNA, high Trop2 protein expression was detected in a larger proportion of cancerous tissues $(66.30 \%)$ than in neighboring non-cancerous tissues (43.8\%). Furthermore, Trop2 overexpression predicted poor overall and disease-free survival. This is similar to the findings of Muhlmann et al., who reported that increased Trop2 expression accompanied poor disease-free and overall survival rates in patients with advanced intestinal-type carcinoma [14].

Although Muhlmann and colleagues also studied the relationship between Trop2 expression and GC, they used the Lauren classification, which only distinguishes between intestinal-type and diffuse-type cancers [14]. Here, we divided the $600 \mathrm{GC}$ cases into several types according to the latest WHO classification guidelines [36]: tubular, mixed (tubular and mucinous), mucinous,
Signet ring cell, and other (papillary adenocarcinoma, adeno-squamous carcinoma, squamous cell carcinoma, undifferentiated carcinoma, and neuroendocrine carcinoma). We found that Trop2 was overexpressed in all GC tissues with the exception of Signet ring cells. However, future studies examining higher numbers of each sample type could help clarify the impact of Trop2 in GC. Additionally, the molecular characteristics and epidemiology of GC vary between eastern and western countries [37-38]. The incidence of different types of GC has also changed over time [39]. Therefore, identifying the molecular characteristics of the various GC types in different populations could potentially increase the efficacy of targeted therapies.

$\mathrm{GC}$ is the most prevalent digestive system malignancy in the world, and China has more GC patients than any other country. Moreover, $40 \%-80 \%$ of the population in China is H. pylori-positive, but only a small proportion of infected patients develop GC [40]. Several
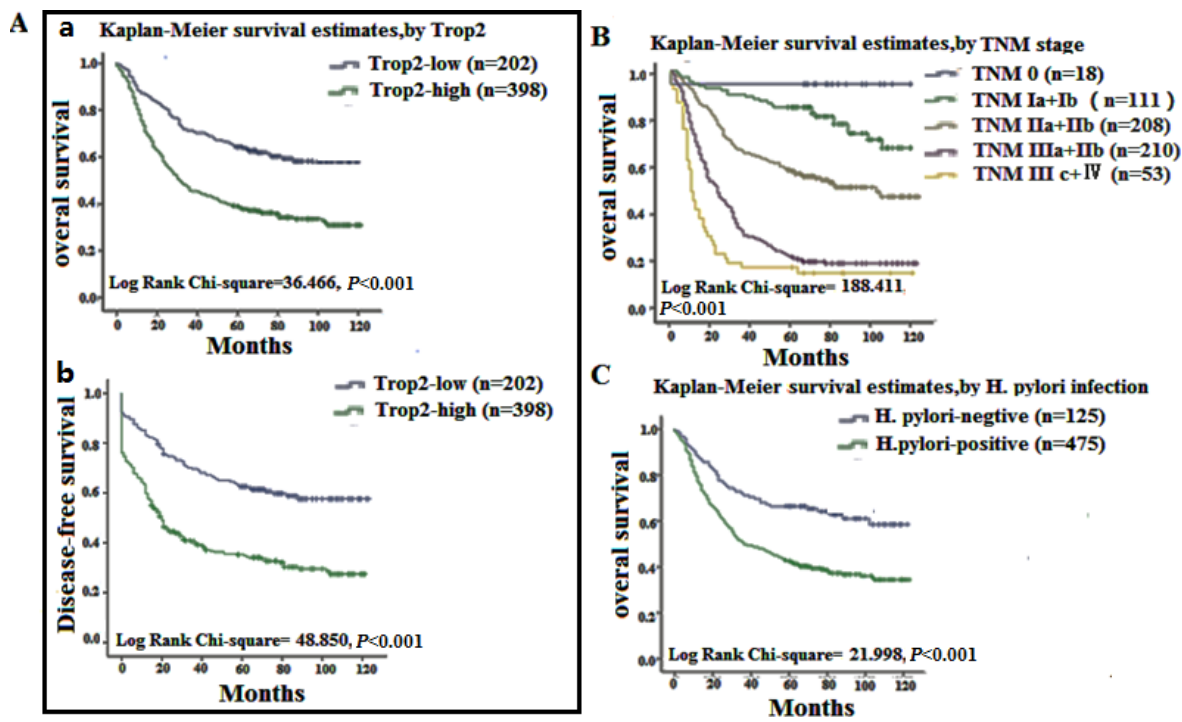

Figure 3: Survival curves for gastric cancer using the Kaplan-Meier method and the log-rank test. (A); a Overall survival curves for patients with low or no Trop2 expression (blue line, 1) and patients with high Trop2 expression of (green line, 2); b disease-free survival curves for patients with low or no Trop2 expression (blue line, 1) and high Trop2 expression (green line, 2). (B) Overall survival curves by TNM stage; TNM 0 (blue line, 1), TNM Ia and Ib (green line, 2), TNM IIa and IIb (grey line, 3), TNM IIIa and IIIb ( purple line, 4), TNM IIIc and IV (yellow line, 5). (C) overall survival curves for H. pylori negative (blue line, 1) and positive (green line, 2) patients. 
reports have suggested that $H$. pylori infection can induce genetic and signaling pathway changes [5]. We found here that $H$. pylori infection was associated with high Trop2 expression and poor overall survival. It is possible that $H$. pylori infection may induce Trop2 overexpression, but the mechanism behind this induction needs to be explored in future studies.

Interestingly, our data also show that Trop2 may be more frequently overexpressed in intestinal metaplasia (IM) $(80 \%)$ than in GC tissues $(66.30 \%)$. This difference did not reach statistical significance, perhaps due to the small number of IM cases examined ( $n=30$ vs $n=600$ for GC). Gastric mucosa IM lesions can develop into GC (intestinal-type) [41], and chronic gastritis can progress through AG, IM, and dysplasia to eventually result in GC [42]. However, Trop2 expression was elevated in only $29.03 \%$ of low-grade and $37.50 \%$ of high-grade intra-epithelial neoplasia tissues. Further studies will be necessary to determine the role of Trop2 in the progression from IM to GC. However, our results suggest that high Trop2 expression is related to poor prognosis in $\mathrm{GC}$, and monitoring this biomarker may aid in the treatment of GC.

\section{METHODS}

\section{Human tissue specimens and patient clinical information}

A total of 830 formalin-fixed, paraffin-embedded (FFPE) stomach tissue samples were collected from 741 patients. This included 600 cancer tissues with 89 matched tumor neighbor tissues, and 32 chronic gastritis, 30 intestinal metaplasia, 31 low-grade intraepithelial neoplasia, and 48 high-grade intraepithelial neoplasia tissues. All tissue blocks were received from the Department of Pathology at the Affiliated Hospital of Nantong University between 2003 and 2010. Medical records for tissue donor patients included information on age, sex, Tumor Node Metastasis (TNM) stage, histological type, differentiation grade, and $H$. pylori infection. No patients received treatment (radiation therapy, chemotherapy, or immunotherapy) before surgical resection. Overall survival (OS) was defied as the period from initial diagnosis via biopsy to death. Information on patients who were alive at the last follow-up date were deleted from the analysis. Disease-free survival (DFS) was defied as the period from follow-up to recurrence. Fortyone additional freshly frozen gastric cancer and matching tumor neighbor tissues were obtained primarily from the First Affiliated Hospital of Nanjing Medical University. Tissues from Huai'an Second People's Hospital, Zhangjiagang AoYoung Hospital, and Affiliated Hospital of Nantong University were also included in this study. The study protocol was approved by the Human Research Ethics Committees of these hospitals.

\section{Tissue microarrays (TMA) and immunohistochemistry analysis (IHC)}

The TMAs were generated in the Department of Pathology, Nantong University Affiliated Hospital, Nantong, Jiangsu, China, using the Tissue Microarrayer System Quick Ray (UT06, UNITMA, Korea) manual. Specifically, core tissue biopsies ( $2 \mathrm{~mm}$ in diameter) were taken from 70 individuals. FFPE blocks were made and then arranged in new recipient paraffin blocks. A total of 13 gastric TMAs were made. Four-micron sections were cut and placed on super frost-charged glass microscope slides to generate TMA slides. Tissue sections were deparaffinized and rehydrated through graded alcohols. Endogenous peroxidase activity was blocked by incubation in $3 \% \mathrm{H}_{2} \mathrm{O}_{2}$. Tissues were placed in 0.01 $\mathrm{M}$ citrate buffer, $\mathrm{pH} 6.0$, and heated in a microwave for antigen retrieval. Trop2 was detected using a polyclonal goat anti-human Trop2 antibody (dilution 1:200) (R \& D, AF650). Reactions were detected with an Envision ${ }^{\mathrm{TM}}$ peroxidase kit (Dako, Carpinteria, CA, USA). Tissues were then incubated in 3, 3'-diaminobenzidine plus (Dako, Carpinteria, CA, USA), counterstained with Hematoxylin, dehydrated through graded alcohols, cleared in xylene, and coverslipped with permanent mounting media. Staining was quantified in all tissues without knowledge of clinical characteristics. Trop2 expression was scored using the semi-quantitative $\mathrm{H}$-score method, which takes into account both the staining intensity and the percentage of cells at that intensity [43-44]. The following staining intensity scores were used: 0 indicated no staining; $1+$ indicated weak staining; $2+$ indicated moderate staining; and $3+$ indicated intense staining. The total number of cells at each intensity level was multiplied by the corresponding intensity score to yield an intensity percentage score. Final staining scores were then calculated by summing the four intensity percentage scores; the minimum possible final staining score was 0 (no staining), and maximum possible score was 300 ( $100 \%$ of cells with $3+$ staining intensity).

\section{Quantitative real-time polymerase chain reaction (qRT-PCR)}

qRT-PCR was performed to determine Trop2 mRNA expression levels in 41 pairs of human GC tissue and matched tumor neighbor tissue. Tissue samples were snap-frozen in liquid nitrogen and stored at $-80^{\circ} \mathrm{C}$ before RNA extraction. Total RNA was extracted from frozen samples using Trizol reagent (Invitrogen, Carlsbad, CA, USA) and reverse transcribed into cDNA using a PrimeScript ${ }^{\mathrm{TM}}$ RT reagent kit (Takara, Glen Burnie, MD) in accordance with the manufacturer's instructions. Human $\beta$-actin served as the internal control for determining Trop 2 mRNA levels. The following primers were used for PCR reactions: human $\beta$-actin forward, 5'- TGGAGAAAATCTGGCACCAC-3', and 
reverse, 5'-GATGATGCCTCGTTCTAC-3', and Trop2 forward, 5'-TGTCCTGATGTGATATGTCTGAG-3', and reverse, 5'-GGGTGAGAGTGGGTTGGG-3' (Genescript. Nanjing, China). qPT-PCR was performed on an ABI PRISM 7500HT Sequence Detection System (Applied Biosystems, Foster City, CA, USA) in 96-well plates. The final volume for each reaction was $20 \mu \mathrm{L}$, which included $2 \mu \mathrm{L}$ of cDNA template (corresponding to $\sim 40 \mathrm{ng}$ of retrotranscribed total RNA), the primers $(20 \mathrm{nmol} / \mathrm{L}$ each) and $2 \times$ SYBR Green PCR Master Mixture $(10 \mu \mathrm{L}$; Applied Biosystems). Cycle conditions were as follows: after an initial 2-minute hold at $50^{\circ} \mathrm{C}$ to allow AmpErase-UNG activity and $10 \mathrm{~min}$ at $95^{\circ} \mathrm{C}$, the samples were cycled 40 times at $95^{\circ} \mathrm{C}$ for 15 seconds and $58^{\circ} \mathrm{C}$ for 1 minute. All experiments were performed in triplicate. Results were normalized to respective internal controls. The $\mathrm{Ct}$-value for each sample was calculated using the $\Delta \Delta \mathrm{Ct}$ method [45-48], and results were expressed as $2^{-\Delta \Delta C t}$.

\section{Statistical analysis}

All statistical analyses were carried out using the SPSS 18.0 statistical software package (SPSS Inc., Chicago, IL). The two groups were compared using unpaired Student's $t$-test. For statistical analysis, the continuous Trop2 expression data from IHC were first converted into dichotic data (low vs high) using specific cutoff values, which were selected based on significant differences in overall survival (OS) using the X-tile software program (The Rimm Lab at Yale University; http://www.tissuearray.org/rimmlab) [35]. Student's $t$-test and $\chi^{2}$ test $(T<1$ or $n<40$, Fisher's exact test) were used to determine the statistical significance of differences between the groups. Cumulative patient survival was estimated using the Kaplan-Meier method, and a logrank test was used to compare the survival curves. A Cox proportional hazards model was used to calculate univariate and multivariate hazard ratios for the variables. Values of $p$ less than 0.05 were considered statistically significant.

\section{ACKNOWLEDGMENTS AND FUNDING}

This work was supported by grants from the National Natural Science Foundation of China (No. 81201596), the Special Fund of Clinical Medicine in Jiangsu Province (No. 2013038) and the Priority Academic Program Development of Jiangsu Higher Education Institutions.

\section{REFERENCES}

1. Du M, Wang W, Jin H, Wang Q, Ge Y, Lu J, Ma G, Chu H, Tong N, Zhu H, Wang M, Qiang F, Zhang Z. The association analysis of lncRNA HOTAIR genetic variants and gastric cancer risk in a Chinese population. Oncotarget. 2015; 6:31255-62. doi:10.18632/oncotarget.5158.

2. Liu L, Chen Q, Lai R, Wu X, Liu F, Xu G, Ji Y. Elevated expression of mature miR-21 and miR-155 in cancerous gastric tissues from Chinese patients with gastric cancer. J Biom Res. 2010; 24:187-197.

3. Sun R, Wang X, Zhu H, Mei H, Wang W, Zhang S, Huang J. Prognostic value of LAMP3 and TP53 overexpression in benign and malignant gastrointestinal tissues. Oncotarget. 2014; 5:12398-12409. doi:10.18632/oncotarget.2643.

4. Yoon H, Kim N. Diagnosis and management of high risk group for gastric cancer. Gut and liver. 2015; 9:5-17.

5. Choi YJ, Kim NY, Chang HY, Lee HS, Park SM, Park JH, Shin CH, Kim JM, Kim JS, Lee DH, Jung HC. Helicobacter pylori-induced epithelial-mesenchymal transition, a potential role of gastric cancer initiation and an emergence of stem cells. Carcinogenesis. 2015; 36:553-563.

6. Soichiro S, Wataru S, Shin M. Helicobacter pylori-Induced Signaling Pathways contribute to Intestinal Metaplasia and Gastric Carcinogenesis. Biom Res Int. 2015; 22: 737621-737629.

7. Park YH, Kim N. Review of atrophic gastritis and intestinal metaplasia as a premalignant lesion of gastric cancer. $\mathrm{J}$ Cancer Prev. 2015; 20:25-40.

8. Sue S, Shibata W, Maeda S. Helicobacter pylori-Induced Signaling Pathways Contribute to intestinal Metaplasia and Gastric Carcinogenesis. Bio Med Res Int. 2015; 2015: 737621.

9. Lin JC, Wu YY, Wu, JY, Lin TC, Wu CT, Chang YL, Jou YS, Hong TM, Yang PC. TROP2 is epigenetically inactivated and modulates IGF-1R signalling in lung adenocarcinoma. EMBO Mol Med. 2012; 4:472-485.

10. Wanger TM, Dewitt S, Collins A, Maitland NJ, Poghosyan Z, Knauper V. Differential regulation of TROP2 release by PKC isoforms through vesicles and ADAM17. Cell Signal. 2015; 27:1325-1335.

11. Cubas R, Li M, Chen C, Yao Q. Trop2: a possible therapeutic target for late stage epithelial carcinomas. Biochimica et Biophysica Acta. 2009; 1796:309-314.

12. Tsujikawa M, Kurahashi $H$, Tanaka $T$, Nishida $K$, Shimomura Y, Tano Y, Nakamura Y. Identification of the gene responsible for gelatinous drop-like corneal dystrophy. Nat Genet. 1999; 21:420-423.

13. Fong D, Spizzo G, Gostner JM, Gastl G, Moser P, Krammel C, Gerhard S, Rasse M, Laimer K. TROP2: a novel prognostic marker in squamous cell carcinoma of the oral cavity. Mod path. 2008; 21:186-191.

14. Muhlmann G, Spizzo G, Gostner J, Zitt M, Maier H, Moser P, Gastl G, Muller HM, Margreiter R, Ofner D, Fong D. TROP2 expression as prognostic marker for gastric carcinoma. J Clin Path. 2009; 62:152-158. 
15. Wu H, Xu H, Zhang S, Wang X, Zhu H, Zhang H, Zhu J, Huang J. Potential therapeutic target and independent prognostic marker of TROP2 in laryngeal squamous cell carcinoma. Head \& Neck. 2013; 35:1373-1378.

16. Wang JB, Zhang KH, Grabowska D, Li AM, Dong YY, Day R, Humphrey $\mathrm{P}$, Lewis J, Kladney RD, Arbeit JM, Weber JD, Chung CH, Michel LS. Loss of Trop2 Promotes Carcinogenesis and Features of Epithelial to Mesenchymal Transition in Squamous cell Carcinoma. Mol Cancer Res. 2011; 9:1686-1695.

17. Zhang L, Zhou W, Velculescu VE, Kern SE, Hruban RH, Hamilton SR, Vogelstein B, Kinzler KW. Gene expression profiles in normal and cancer cells. Science. 1997; 276:1268-1272.

18. Lin H, Huang JF, Qiu JR, Zhang HL, Tang XJ, Li H, Wang CJ, Wang ZC, Feng ZQ, Zhu J. Significantly upregulated TACSTD2 and Cyclin D1 correlate with poor prognosis of invasive ductal breast cancer. Exp Mol Path. 2013; 94: 73-78.

19. Agboola AJ, Paish EC, Rakha EA, Powe DG, Macmillan RD, Ellis IO, Green AR. EpCAM expression is an indicator of recurrence in basal-like breast cancer. Breast Cancer Res Treat. 2012; 133:575-582.

20. Benko G, Spajic B, Kruslin B, Tomas D. Impact of the EpCAM expression on biochemical recurrence-free survival in clinically localized prostate cancer. Urol Oncol. 2013; 31: 468-474.

21. Tena-Suck ML, Ortiz-Plata A, Galan F, Sanchez A. Expression of epithelial cell adhesion molecule and pituitary tumor transforming gene in adamantinomatous craniopharyngioma and its correlation with recurrence of the tumor. Ann Diag Path. 2009; 13:82-88.

22. Stepan LP, Trueblood ES, Hale K, Babcook J, Borges L, Sutherland CL. Expression of Trop2 cell surface glycoprotein in normal and tumor tissues: potential implications as a cancer therapeutic target. J Histochem Cytochem. 2011; 59:701-710.

23. Fang YJ, Lu ZH, Wang GQ, Pan ZZ, Zhou ZW, Yun JP, Zhang MF, Wan DS. Elevated expressions of MMP7, TROP2, and survivin are associated with survival, disease recurrence, and liver metastasis of colon cancer. Int $\mathrm{J}$ Colorectal Dis. 2009; 24:875-884.

24. Wang H, Liu QQ, Tang XJ, Xu X, Chu C, Xiong SP, Zheng F, Tong H, Zhu J, Feng ZQ, Lin H. Eukaryotic expression of human anti-TROP2 antibody IgG, its inhibitory effect on cell proliferation of pancreatic cancer. Acta Univ Med Nanjing. 2014; 863-869+882.

25. Liu T, Liu Y, Bao X, Tian J, Yang X. Overexpression of TROP2 predicts poor prognosis of patients with cervical cancer and promotes the proliferation and invasion of cervical cancer cells by regulating ERK signaling pathway. PloS One. 2013; 8:e75864.

26. Shvartsur A, Bonavida B. Trop2 and its overexpression in cancers: regulation and clinical/therapeutic implications.
Genes Cancer. 2015; 6:84-105. doi:10.18632/ genesandcancer.40.

27. Lin H, Zhang HL, Wang J, Lu MP, Zheng F, Wang CJ, Tang XJ, Xu N, Chen RJ, Zhang DW, Zhao P, Zhu J, Mao Y, et al. A novel human Fab antibody for Trop2 inhibits breast cancer growth in vitro and in vivo. Int J Cancer. 2014; 134:1239-1249.

28. Wang H, Liu QQ, Tang XJ, Xu X, Chu C, Xiong SP, Zheng F, Tong H, Zhu J, Feng ZQ, Lin H. Eukaryotic expression of human anti-TROP2 antibody IgG and its inhibitory effect on cell proliferation of pancreatic cancer. Acta Univ Med Nanjing. 2014; (07):863-869+882.

29. Liang J, Liu QQ, Zhang H, Lin H, Tang Q, Liu Y, Su YP, Feng ZQ, Zhu J. Preparation and immunologic characterization of a monoclonal antibody against human trophoblast cell-surface antigen 2. Acta Univ Med Nanjing. 2011; (05):645-650.

30. Lin H, Zhang HL, Liang J, Zhu J, Tang Q, SU YP, Feng ZQ, Guan XH. Expression and characterization of Trop-2 extracellular domain protein of tumor relative antigen. Acta Univ Med Nanjing. 2010; (03):312-315.

31. Wang XY, Lin H, Zhang HH, Qiu JR, Ding GP, Tang XJ, Chen XM, Tang T, Liu QQ, Feng ZQ, Zhu J. Preparation and optimization of human anti-Trop-2 antibody fragment Fab. Acta Univ Med Nanjing. 2012; (01):35-39.

32. Vidmar T, Pavsic M, Lenarcic B. Biochemical and preliminary X-ray characterization of the tumor-associated calcium signal transducer 2 (Trop2) ectodomain. Protein Exp and Pur. 2013; 91:69-76.

33. Huang H, Groth J, Sossey-Alaoui K, Hawthorn L, Beall S, Geradts J. Aberrant expression of novel and previously described cell membrane markers in human breast cancer cell lines and tumors. Clin Cancer Res. 2005; 11: 4357-4364.

34. Guerra E, Trerotola M, Dell' Arciprete R, Bonasera V, Palombo B, El-Sewedy T, Ciccimarra T, Crescenzi C, Lorenzini F, Rossi C, Vacca G, Lattanzio R, Piantelli M, et al. A bicistronic CYCLIN D1-TROP2 mRNA chimera demonstrates a novel oncogenic mechanism in human cancer. Cancer Res. 2008; 68:8113-8121.

35. Lin JC, Wu YY, Wu JY, Lin TC, Wu CT, Chang YL, Jou YS, Hong TM, Yang PC. TROP2 is epigenetically inactivated and modulates IGF-1R signalling in lung adenocarcinoma. EMBO Mol Med. 2012; 4:472-485.

36. Lin ZS, Li Q. The latest 2010 WHO classification of tumors of digestive system. Zhonghua Bing Li Xue Za Zhi. 2011; 40:351-4.

37. Yu Sk, Lenz HJ. Molecular Classification of Gastric Adenocarcinoma: Translating New Insights from The Cancer Genome Atlas Research Network. Curr Treat. Options in Oncol. 2015; 16:17.

38. Qiu M, Zhou Y, Zhang X, Wang Z, Wang F, Shao J, Lu J, Jin Y, Wei X, Zhang D, Wang F, Li Y, Yang D1, Xu R. Lauren classification combined with HER2 status is a better 
prognostic factor in Chinese gastric cancer patients. BMC Cancer. 2014; 7:823.

39. Stiekema J, Cats A, Kuijpers A, van Coevorden F, Boot H, Jansen EP, Verheij M, Balague Ponz O, Hauptmann M, van Sandick JW. Surgical treatment results of intestinal and diffuse type gastric cancer. Implications for a differentiated therapeutic approach? Eur J Surg Oncol. 2013; 39:686-93.

40. Sun P, Du J, Zhu X, Ren C, Xie L, Dai N, Gu Y, Yan C, Dai J, Ma H, Jiang Y, Chen J, Hu Z, et al. Genetic Variation in the 3'-Untranslated Region of NBN Gene Is Associated with Gastric Cancer Risk in a Chinese Population. Plos One. 2015; 10:e139059.

41. Park YH, Kim N. Review of atrophic gastritis and intestinal metaplasia as a premalignant lesion of gastric cancer. $\mathrm{J}$ Cancer Prev. 2015; 20:25-40.

42. Huang H, Wu J, Jin G, Zhang H, Ding Y, Hua Z, Zhou Y, Xue Y, Lu Y, Hu Z, Xu Y, Shen H. A 5'-flanking region polymorphism in toll-like receptor 4 is associated with gastric cancer in a Chinese population. J Biom Res. 2010; 24:100-106.

43. Detre S, Saclani Jotti G, Dowsett M. A “quickscore" method for immunohistochemical semiquantitation: validation for oestrogen receptor in breast carcinomas. J Clin Path. $1995 ; 48: 876-878$.
44. Tang Q, Liu YF, Zhu XJ, Li YH, Zhu J, Zhang JP, Feng ZQ, Guan XH. Expression and prognostic significance of the alpha B-crystallin gene in human hepatocellular carcinoma. Human Path. 2009; 40:300-305.

45. Han L, Jiang B, Wu H, Wang X, Tang X, Huang J, Zhu J. High expression of CXCR2 is associated with tumorigenesis, progression, and prognosis of laryngeal squamous cell carcinoma. Med Oncol. 2012; 29: 2466-2472.

46. Ni S, Xu L, Huang J, Feng J, Zhu H, Wang G, Wang X. Increased $\mathrm{ZO}-1$ expression predicts valuable prognosis in non-small cell lung cancer. Int J Clin Exp Path. 2013; 6:2887-2895.

47. Zhai X, Zhu H, Wang W, Zhang S, Zhang Y, Mao G. Abnormal expression of EMT-related proteins, S100A4, vimentin and E-cadherin, is correlated with clinicopathological features and prognosis in HCC. Med Oncol. 2014; 31:970.

48. Wang Y, Chen D, Qian H, Tsai YS, Shao S, Liu Q, Dominguez D ang Wang Z. The Splicing Factor RBM4 Controls Apoptosis, Proliferation, and Migration to Suppress Tumor Progression. Cancer Cell. 2014; 26: 374-89. 